\title{
Combined Medication with Stimulants and Non-stimulants for Attention-deficit/hyperactivity Disorder
}

\author{
Geon Ho Bahn', Kyunghoon Seo ${ }^{2}$ \\ ${ }^{1}$ Deparment of Psychiatry, Kyung Hee University School of Medicine, ${ }^{2}$ Department of Psychiatry, Kyung Hee University Hospital, Seoul, Korea
}

Objective: To study the efficiency and indication of combined medication with a stimulant and non-stimulant for attention-deficiency/hyperactivity disorder (ADHD), herein, the authors examined children and adult patients with ADHD. Methods: Subjects included patients diagnosed with ADHD who paid two or more visits to the outpatient clinic of the Kyung Hee University hospital from January 2009 to December 2019. The authors examined the age, sex, drugs, treatment adherence, and reason for combined medication. The subjects were classified into four groups: treatment with a non-stimulant (atomoxetine) only (Group ATX), treatment with a stimulant (methylphenidate immediate-release, extended-release, or osmotic-release oral system) only (Group MPH), exposed to both but separately used (Group SEP), and exposed to both with combined use (Group COM). The patient was considered adherent to treatment (1) on visiting the hospital ten or more times or consecutively for six months, and (2) medication possession ratio $\geq 0.8$.

Results: Of 929 patients, 229 (24.7\%) were female. Group ATX comprised 146 (15.7\%) patients, Group MPH comprised $627(67.5 \%)$ patients, Group SEP comprised 106 (11.4\%) patients, and Group COM comprised 50 (5.4\%) patients. Longer-term adherence was seen with combined medication and in females than with monopharmacy and in males. The main indication for combination was dose-limiting untoward effects.

Conclusion: These results suggest that combined medication would facilitate treatment adherence for ADHD. Further research is essential for the replication of these results in a large sample and the investigation of the indications for administering combined medication in children and adults with ADHD.

KEY WORDS: Polypharmacy; Attention deficit hyperactivity disorder; Atomoxetine; Methylphenidate; Pharmacotherapy; Adult.

\section{INTRODUCTION}

Drugs approved by the U.S. Food and Drug Administration (FDA) for attention-deficit/hyperactivity disorder (ADHD) are amphetamine and methylphenidate $(\mathrm{MPH})$ as central nervous system stimulants and atomoxetine (ATX) as a non-stimulant [1]. Methylphenidate is a predominantly dopaminergic drug and acts as a norepinephrine-dopamine reuptake inhibitor. Atomoxetine is a selective nor-

Received: November 3, 2020 / Revised: January 1, 2021

Accepted: January 2, 2021

Address for correspondence: Geon Ho Bahn

Department of Psychiatry, Kyung Hee University School of

Medicine, 26 Kyungheedae-ro, Dongdaemun-gu, Seoul 02447,

Korea

E-mail: mompeian@khu.ac.kr

ORCID: https://orcid.org/0000-0002-3550-0422

*The theme of this article was presented with poster in the 24th

World Congress of IACAPAP, Virtual, 2-4 December 2020, Singapore. epinephrine reuptake inhibitor [2]. The response rate of monopharmacy with these drugs reaches $70 \%$; however, there are cases with a partial response, less effect than expected, and good effect but with serious side effects [1,3]. Some parents refuse pharmacotherapy because they are afraid of uncertain complications of the drugs that could affect their children [4]. Unlike children, adult patients can decide by themselves whether to use medication or not because they are more likely to refuse medications owing to side effects such as sleep disturbance and sexual dysfunction [5]. Therefore, a treatment strategy is required for these treatment resistant and reluctant patients.

There is a growing interest and need for combined medication because of non-responders to monopharmacy or reluctance towards medication due to drug side effects; however, there is not enough research or data about drug combination [6]. One of the reasons for the lack of data on drug combination is that the U.S. FDA has not ap-

(c) This is an Open-Access article distributed under the terms of the Creative Commons Attribution Non-Commercial License (http://creativecommons.org/licenses/by-nc/4.0) which permits unrestricted non-commercial use, distribution, and reproduction in any medium, provided the original work is properly cited. 
proved the combination of more than one anti-ADHD medication for the treatment of ADHD, so it has not been insured and has been prescribed at the patient's own expense [7]. Although the Health Insurance Review and Assessment Service (HIRA) in the Republic of Korea did not provide insurance coverage for combined medication for $A D H D$, it began to serve insurance benefits to prescribe two anti-ADHD medications, each with a different mechanism of action, on December 1, 2019 [8]. Another reason for the lack of research data on combined medication may be that children were the main subjects for the treatment of ADHD treatment, and prescribing drugs combined without sufficient evidence was cautiously done [9].

Brown [10] reported four cases in which the combination therapy of ATX and stimulants was effective for ADHD to extend the symptom relief period without side effects or to alleviate a wider range of impairment than monopharmacy. In a comparative study between monopharmacy and combined medication with MPH and ATX, although more side effects occurred with the use of combined medication, most of them were generally tolerable [9]. In a study investigating the efficacy, safety, and tolerability of the combined therapy of MPH and ATX, symptoms were improved significantly in nine out of twelve patients, and the combined therapy enhanced the effectiveness of monotherapy [11].

Previous studies were conducted with a small number of subjects, mostly children and adolescents, and the duration of drug maintenance was short. Therefore, this study investigated the clinical characteristics of long-term combined medication for patients with ADHD, including children and adults.

\section{METHODS}

\section{Subjects}

A total of 1,189 outpatients, aged $2-74$ years who visited the Kyung Hee University Hospital between January 2009 and December 2019 were included in this study. To be eligible for this study, patients had to meet the following criteria: diagnosis of $\mathrm{ADHD}$, any type, by psychiatrists in accordance with the Diagnostic and Statistical Manual of Mental Disorders 4th edition (DSM-IV) [12] and DSM-5 [13] diagnostic criteria, and visit to the outpatient clinic at least twice. Those in whom ADHD was not the primary diagnosis were excluded from this study.

\section{Methods}

The authors collected data on the sex, age, drug, and treatment adherence of each patient by reviewing their medical records. The age was evaluated based on the date when ADHD was first diagnosed. The subjects were classified into two groups: over and below 18 years of age. The reason for choosing 18 years as the standard age is that the standards of the HIRA for the ADHD drug treatment changed over the study period [8]. Until December 2012, patients over 18 years of age could not receive medications under insurance even if they were diagnosed with ADHD [14]. From January 2013, patients younger than 18 years of age diagnosed with ADHD could receive insurance benefits after the age of 18 years, and from September 2016, the age for receiving insurance benefits for the use of non-stimulants and stimulants was changed to $6-65$ years [8]. Owing to these variables, age-specific comparisons were made with 18 years set as the standard age, taking into account the instability of the data. While most patients included were aged 6 years and older as in the insurance policy, children who had severe behavioral problems, including extreme hyperactivity, violence against peers, and highly shortened sleep duration, were allowed to take medications even under the age of 5 years under the supervision of HIRA. Therefore, the youngest patient included in the study was aged 2 years.

This study focused on non-stimulants such as ATX and stimulants such as the MPH immediate-release formulation (MPH IR), MPH extended-release formulation (MPH $\mathrm{ER}$ ), and MPH osmotic-release oral system (MPH OROS). The subjects were divided into four groups: Group ATX, monotherapy with ATX only; Group MPH, monotherapy with MPH IR, ER, or OROS; Group SEP, alternative prescription of MPH and ATX; and Group COM, the combined use of non-stimulants and stimulants.

Treatment duration was calculated as the time and frequency of visiting the hospital from the day of diagnosis of ADHD to the day of treatment cessation. A patient was considered adherent to treatment on visiting the outpatient clinic more than six months or on paying ten or more visits to the outpatient clinic after the first prescription. Those with a medication possession ratio less than 0.8 were considered drop-outs. These inclusion and exclusion criteria were based on the authors' previous study 
Table 1. Demographic and clinical characteristics according to the type of pharmacotherapy

\begin{tabular}{|c|c|c|c|c|c|c|}
\hline Variable & ATX & $\mathrm{MPH}$ & SEP & $\mathrm{COM}$ & Total & $p$ value \\
\hline \multicolumn{7}{|l|}{ Subjects and sex } \\
\hline Total & $146(15.7)$ & $627(67.5)$ & $106(11.4)$ & $50(5.4)$ & $929(100)$ & \\
\hline Male & $120(82.2)$ & $460(74)$ & $82(77.4)$ & $38(76)$ & $700(75.3)$ & 0.1543 \\
\hline Female & $26(17.8)$ & $167(26)$ & $24(22.6)$ & $12(24)$ & 229 & \\
\hline \multicolumn{7}{|l|}{ Age (yr) } \\
\hline$<18$ & 109 (74.7) & $464(74)$ & 77 (72.6) & $42(84)$ & $692(74.5)$ & 0.4487 \\
\hline$\geq 18$ & $37(25.3)$ & $163(26)$ & $29(27.4)$ & $8(16)$ & 237 & \\
\hline \multicolumn{7}{|l|}{ Outcome } \\
\hline Discontinuation (or dropout) & $116(79.4)$ & $509(81.2)$ & $75(70.8)$ & $29(58)$ & $722(77.7)$ & 0.0003 \\
\hline Maintenance & $30(20.6)$ & $118(18.8)$ & $31(29.2)$ & $21(42)$ & 207 & \\
\hline Number of OPD visit & $22.7 \pm 25.5$ & $20.1 \pm 21.6$ & $39.5 \pm 36.6$ & $45.1 \pm 38.2$ & $24.1 \pm 26.6$ & $<0.0001$ \\
\hline Treatment duration (yr) & $1.87 \pm 2.28$ & $2.38 \pm 2.78$ & $3.85 \pm 2.98$ & $4.56 \pm 3.72$ & $2.58 \pm 2.88$ & $<0.0001$ \\
\hline
\end{tabular}

Values are presented as number (\%) or mean \pm standard deviation.

ATX, group treated with atomoxetine only; MPH, group treated with methylphenidate only; SEP, group exposed to ATX and MPH but separately used; COM, group exposed to ATX and MPH with combined use; OPD, outpatient department.

[15] in which the treatment cessation rate exceeded $40 \%$ on a six-month visit or the tenth visit after initial exposure to the medication.

In this study, by reviewing and analyzing the contents of the medical records, the authors examined the cause of drug combination and one or more reasons per person were admitted.

All patients were started on medications after laboratory tests including electrocardiography, aspartate aminotransferase and alanine aminotransferase level evaluation, thyroid hormone levels (tri-iodothyronine, free thyroxine, thyroid-stimulating hormone), and complete blood count, to confirm the absence of physical disabilities. This study was approved by the Institutional Review Board of the Kyung Hee University Hospital (KHUH 2020-03-055). Written informed consent from the subjects was exempted because this study was a retrospective chart review of the patients.

\section{Statistical Analysis}

Chi-square tests were conducted to determine the differences in categorical variables, sex, age, and maintenance of treatment, among the four groups (MPH, ATX, COM, and SEP). The Kruskal - Wallis test was performed to examine the group difference according to the continuous variables, frequency and duration of the treatment, and multiple comparisons were performed through the Bonferroni post hoc analysis. Interaction effect among the types of medication used, sex, and age was examined by interaction analysis, and subgroup analysis was additionally confirmed according to sex and age. The Kaplan-Meier analysis was performed to analyze the influence on treatment maintenance, and multiple Cox regression that adjusted for age and sex was also performed. Statistical analysis was performed using SAS 9.4 (Statistical Analysis System version 9.4; SAS Institute Inc., Cary, NC, USA), and a value of 0.05 was considered statistically significant.

\section{RESULTS}

Of the 1,189 patients, 260 were excluded because they were not exposed to any anti-ADHD medication. Then, 929 patients (age range, $2-74$ years) were included as subjects in the final analysis, of which 229 (24.7\%) were female. There were no significant differences in sex and age between the patients excluded and those included in the analysis (sex, $p$ value $=0.2378$; age, $p$ value $=0.6588$ )

Among the 929 patients, Group MPH comprised 627 (67.5\%), Group ATX comprised 146 (15.7\%), Group SEP comprised 106 (11.4\%), and Group COM comprised 50 $(5.4 \%)$ patients (Table 1$)$. There were no significant differences in sex and age among the four groups. Treatment frequency and duration, and outcome were significantly higher in Group COM and Group SEP than in the monopharmacy groups (Table 1). In the analysis of the effect for medication adherence, monopharmacy groups showed significantly higher hazard ratio of discontinuation of medication than Group COM and Group SEP (Table 2). The risk of discontinuance of medication is 1.21 times higher significantly in the subjects over 18 years of age 
Table 2. Statistical analysis to determine the significant way of pharmacotherapy for ADHD

\begin{tabular}{|c|c|c|c|c|c|c|c|c|c|c|}
\hline \multirow[t]{2}{*}{ Variable } & \multicolumn{4}{|c|}{ Survival duration (yr) } & \multicolumn{3}{|c|}{$\begin{array}{l}\text { Simple cox regression } \\
\text { (ref. maintenance) }\end{array}$} & \multicolumn{3}{|c|}{$\begin{array}{l}\text { Multiple cox regression } \\
\text { (ref. maintenance) }\end{array}$} \\
\hline & Median & $\mathrm{Cl}$ & Mean & SE & $\mathrm{HR}$ & $\mathrm{Cl}$ & $p$ value & HR & $\mathrm{Cl}$ & $p$ value \\
\hline \multicolumn{11}{|l|}{ Group } \\
\hline ATX and MPH & 1.44 & $1.24-1.68$ & 2.86 & 0.13 & 1.00 & - & - & 1.00 & - & - \\
\hline $\mathrm{COM}$ & 5.84 & $2.65-10.41$ & 6.00 & 0.65 & 0.39 & $0.27-0.57$ & $<0.0001$ & 0.40 & $0.27-0.58$ & $<0.0001$ \\
\hline SEP & 3.78 & $2.76-4.95$ & 4.72 & 0.37 & 0.57 & $0.45-0.73$ & $<0.0001$ & 0.57 & $0.45-0.73$ & $<0.0001$ \\
\hline \multicolumn{11}{|l|}{ Sex } \\
\hline Male & 1.76 & $1.53-2.16$ & 3.37 & 0.14 & 1.00 & - & - & 1.00 & - & - \\
\hline Female & 1.61 & $1.24-2.15$ & 2.88 & 0.23 & 1.15 & $0.97-1.37$ & 0.0986 & 1.16 & $0.98-1.37$ & 0.0930 \\
\hline \multicolumn{11}{|l|}{ Age } \\
\hline$<18$ & 1.90 & $1.64-2.28$ & 3.40 & 0.14 & 1.00 & - & - & 1.00 & - & - \\
\hline$\geq 18$ & 1.25 & $0.91-1.53$ & 2.84 & 0.25 & 1.24 & $1.05-1.47$ & 0.0137 & 1.21 & $1.02-1.44$ & 0.0270 \\
\hline
\end{tabular}

ADHD, attention-deficiency/hyperactivity disorder; ATX, group treated with atomoxetine only; MPH, group treated with methylphenidate only; SEP, group exposed to ATX and MPH but separately used; COM, group exposed to ATX and MPH with combined use; Cl, confidence interval; HR, hazard ratio; SE, standard error.

Table 3. Interaction analysis according to sex and age among groups

\begin{tabular}{|c|c|c|c|c|c|c|c|c|c|c|c|c|}
\hline \multirow{2}{*}{ Sub-group } & \multicolumn{2}{|c|}{ Variable } & \multicolumn{4}{|c|}{ Survival duration (yr) } & \multicolumn{3}{|c|}{$\begin{array}{l}\text { Multiple cox regression } \\
\text { (ref. maintenance) }\end{array}$} & \multicolumn{3}{|c|}{ Interaction analysis ${ }^{\mathrm{a}}$} \\
\hline & & & Median & $\mathrm{Cl}$ & Mean & SE & $\mathrm{HR}$ & $\mathrm{Cl}$ & $p$ value & $H R$ & $\mathrm{Cl}$ & $p$ value \\
\hline \multirow{2}{*}{$\begin{array}{c}\text { ATX and } \\
\mathrm{MPH}\end{array}$} & \multirow[t]{6}{*}{ Sex } & Male & 1.47 & $1.23-1.74$ & 2.99 & 0.15 & 1.00 & - & - & 1.00 & - & - \\
\hline & & Female & 1.41 & $0.85-1.85$ & 2.46 & 0.22 & 1.18 & $0.98-1.41$ & 0.0772 & & & \\
\hline \multirow[t]{2}{*}{$\mathrm{COM}$} & & Male & 5.36 & $1.76-8.75$ & 5.51 & 0.70 & 1.00 & - & - & 0.34 & $0.12-0.99$ & 0.0481 \\
\hline & & Female & 10.67 & $0.43-\mathrm{ND}$ & 7.92 & 1.56 & 0.19 & $0.05-0.70$ & 0.0131 & & & \\
\hline \multirow[t]{2}{*}{ SEP } & & Male & 3.78 & $3.00-6.70$ & 4.95 & 0.42 & 1.00 & - & - & 1.16 & $0.65-2.04$ & 0.6190 \\
\hline & & Female & 2.94 & $0.73-5.30$ & 3.77 & 0.70 & 1.53 & $0.88-2.66$ & 0.1302 & & & \\
\hline \multirow{2}{*}{$\begin{array}{c}\text { ATX and } \\
\mathrm{MPH}\end{array}$} & Age (yr) & $<18$ & 1.62 & $1.38-1.87$ & 2.98 & 0.15 & 1.00 & - & - & 1.00 & - & - \\
\hline & & $\geq 18$ & 1.10 & $0.72-1.36$ & 2.50 & 0.25 & 1.21 & $1.01-1.46$ & 0.0410 & & & \\
\hline \multirow[t]{2}{*}{$\mathrm{COM}$} & & $<18$ & 7.53 & $2.87-10.41$ & 6.40 & 0.68 & 1.00 & - & - & 1.60 & $0.60-4.30$ & 0.3505 \\
\hline & & $\geq 18$ & 0.91 & $0.10-\mathrm{ND}$ & 1.14 & 0.35 & 6.85 & $1.94-24.25$ & 0.0029 & & & \\
\hline \multirow[t]{2}{*}{ SEP } & & $<18$ & 3.67 & $2.68-5.30$ & 4.79 & 0.43 & 1.00 & - & - & 0.87 & $0.50-1.51$ & 0.6222 \\
\hline & & $\geq 18$ & 3.78 & $2.15-7.05$ & 4.18 & 0.57 & 1.17 & $0.69-1.99$ & 0.5653 & & & \\
\hline
\end{tabular}

ATX, group treated with atomoxetine only; MPH, group treated with methylphenidate only; SEP, group exposed to ATX and MPH but separately used; COM, group exposed to ATX and MPH with combined use; $\mathrm{Cl}$, confidence interval; $\mathrm{HR}$, hazard ratio; SE, standard error; ND, not detected. ${ }^{a}$ Wilcoxon rank sum test, adjusted by age, sex.

than those less than 18 years old. In terms of interaction, adherence to treatment in Group COM was significantly better in females than in males (Table 3).

For the analysis of the reason for combination, the authors focused on 21 patients (12 males, 9 females) who were adherent to treatment in the Group COM (Table 1). There were the 32 reasons for combination therapy: 16 patients with untoward effects, seven with a partial response (less effectiveness with enough dosage for bodyweight and age), six with associated disorders (i.e., sleep disorders and tic), and three for controlling non-ADHD symptoms (i.e., behaviors in patients with low intelligence or autistic characteristics) (Table 4).

\section{DISCUSSION}

Combined medication with anti-ADHD drugs was significantly effective for the long-term compliance with treatment for ADHD than monopharmacy, in terms of the frequency and duration of the treatment in this study. This result cannot be generalized to the treatment for $\mathrm{ADHD}$; however, it can be interpreted that combined medication is effective in some patients who did not sufficiently improve with monotherapy. This is because the mono- 
Table 4. Reasons for drug combination among 21 long-term follow-up patients in group COM

\begin{tabular}{lc}
\hline \multicolumn{1}{c}{ Reason for combination } & $\begin{array}{c}\text { Number of } \\
\text { comments }^{\mathrm{a}}\end{array}$ \\
\hline Untoward effects & \\
Depressive mood & 4 \\
Irritability & 4 \\
Appetite loss & 3 \\
Psychotic change & 2 \\
Somatic symptoms & 2 \\
[Blunting of effect] Zombie like changes & 1 \\
Less effective with enough dosage for body weight & 7 \\
Associated disorders & 6 \\
Non-ADHD symptom control & 3 \\
\hline
\end{tabular}

COM, combined use of methylphenidate and atomoxetine; ADHD, attention-deficiency/hyperactivity disorder.

${ }^{a}$ Comments about the reason for combination can be duplicated per person.

therapy response rate of $\mathrm{MPH}$ drugs is around $70 \%$ and increases to $90 \%$ when dextroamphetamines are included [5]. It is also necessary to consider that combination therapy is being applied to very few cases compared with monotherapy. In this study, $5.4 \%$ of patients were using MPH and ATX at the same time. In a Turkish university hospital, 12 patients $(1.45 \%)$ among 824 patients with ADHD were treated with combinations of MPH and ATX [11]. Based on big data from the Danish Registry, treatment with $2 \%$ of MPH overlapped treatment with ATX [16]. After the introduction of MPH ER in the Netherlands, the switch from MPH IR to MPH ER and the addition of MPH ER to MPH IR have lowered the rate of discontinuation of medications, which indirectly proves the effectiveness of the combined medication [17]. When MPH IR reacted partially in patients with ADHD, MPH IR and MPH ER were used together to increase the duration and extent of therapeutic effect for partial responders to monotherapy [1].

In terms of prevalence, the male to female ratio is $2: 1$ in childhood and 1.6:1 in adulthood [13]. In a Swedish study, the overall dispensing prevalence increased with an average of $53 \%$ yearly among women aged $22-45$ years, and this result is probably an indication of increased awareness among affected individuals and clinicians about the symptoms and impairments of ADHD in female adults [18]. Girls who are undertreated or undiagnosed in childhood live with their complaints longer, which increase the chance of both a lower educational level and lower productivity at work than in the case of boys who are administered treatment [5]. Because of several failures in both work and relationships, women with ADHD have low self-esteem. As females are usually diagnosed later than males, the results of the treatment are expected to be worse. However, the difference in therapy effects by gender is uncertain. In the authors' previous study, the IQ of the children and mothers' education levels of the group with a long-term treatment of more than three years were significantly lower than those of the early discontinuation group; however, there was no gender difference between the two groups [19]. Additionally, in a total population study in Sweden, there were no significant differences in treatment discontinuation between males and females [18]. In this study, while the treatment adherence was significantly better among females in the combined medication group, there is a limit to generalizing this as a characteristic of ADHD, since the study comprises fewer subjects and is a retrospective chart review. Nevertheless, since female patients are less likely prone to antisocial personality disorder and substance abuse than males [5], it can be assumed that treatment compliance can be better in female patients than in male patients.

In Korea, the combination pharmacotherapy policy in national insurance was changed recently. Since December 2019, despite monopharmacy for ADHD for at least a month, another type of medication for ADHD (MPH, ATX, or clonidine) can be added when physicians decide that the clinical response from the primary drug is insufficient [8]. As other countries have similar situations, there are no proper practice guidelines for combined medication. Adler et al. [1] cited partial response, doselimiting side effects, associated disorders (sleep disturbance and tic disorders), and comorbid disorders as the four main areas in which combinations of medication are used for ADHD. In this study, the most common reason for combined medication among the patients with adherence to treatment was untoward or unexpected effects (dose-limiting side effects) followed by associated disorders such as tic disorder. Although it is known that drugs used for the treatment of ADHD can cause sleep problems or worsen tics, it is possible that physicians did not accurately assess whether these disorders were present before the medication for ADHD was started. From an update review based on standard methodological procedure of Cochrane, although few individuals may exacerbate tics, 
stimulants for ADHD have not been shown worsening tics in most patients with tic [20]. The reason for the high rate of discontinuation of medication within six months after the commencement of medication for ADHD in a university hospital (42.4\%) [19] and the National Health Insurance Claims Data (41.0\%) [15] may be the resistance to untoward effects in the early stages of treatment or deterioration of associated disorders, despite the improvement of ADHD-related symptoms with medication.

Among the subjects of this study, some cases were treated with combined medication because of less effectiveness with enough dosage for bodyweight, or less effectiveness by the limitation of dosage in the insurance policy. Especially for children, MPH dosage may be insufficient if the age and weight standards are met. Therefore, the application of combined medication may be necessary for overweight children to comply with the health insurance regulations on drug treatment [21].

Under the insurance policy, the criteria for determining drug dosage depend on weight and age; however, there are no requirements for appropriate standards for the period of drug titration. Muit et al. [22] reported a 120-day period until the establishment of the optimal pharmacological treatment for adults with ADHD. The retrospective study of one university hospital showed a significant difference in the time from the first visit to the clinic to the start of medication between the early drop-out group and the treatment continuation group, $36.8 \pm 26.8$ days and $57.4 \pm 46.0$ days, respectively [23]. The slower the onset of the medication, the higher the treatment continuation rate is. If the duration to titrate the dose of a drug can be set correctly, we can consider a combined medication when the first drug is ineffective within the appropriate period of titration.

As more than half of the children and adults with ADHD have psychiatric comorbidities [8], physicians have to consider psychiatric symptoms beyond ADHD while setting up the combined medication regimen. In this study, few patients with neurodevelopmental disorders such as intellectual disability were treated with combined drugs to treat behavioral problems. Based on the clinical guidelines for the treatment of ADHD for people with intellectual disability, MPH, and ATX at higher doses have shown clear benefits in behavioral and/or cognitive domains [24].

Results in this study should be interpreted in the context of limitations. First, as this was a retrospective study of the medical records, there were no randomly matched control groups, and the authors did not use any objective measurement tools to evaluate symptom changes or response rates for the medication. Second, there was no comparison depending on the types of MPH formulations, i.e., IR, ER, and OROS. Third, in patients over 18 years of age, there may be a problem with the stability of the data due to changes in the HIRA standards during the study period. Given these limitation, although the results of this study suggested that the combined medication for ADHD may be beneficial, a large-scale study of the mechanism, effectiveness and safety of the combination with stimulant and non-stimulant is urgently needed to ensure the generalization of the findings is possible.

To the best of the authors' knowledge, this is the first study to conduct a factor analysis and indication analysis that affects the long-term follow-up of combined medication with MPH and ATX in children and adults with ADHD.

Combined pharmacotherapy with MPH and ATX, especially in females, would be beneficial for adherence to treatment for ADHD. Indications for combined medication are dose-limiting untoward effects, a partial response including less effectiveness with enough dosage for the bodyweight or by the limitation of dosage in the insurance policy, associated disorders, and control of non-ADHD symptoms. Further research is essential for the practice guidelines of the combined medication for ADHD.

\section{- Conflicts of Interest}

No potential conflict of interest relevant to this article was reported.

\section{Author Contributions}

Conceived and designed the study: Geon Ho Bahn. Performed the study: Geon Ho Bahn, Kyunghoon Seo, Analyzed the data: Kyunghoon Seo. Wrote the first draft of the manuscript: Geon Ho Bahn. Revision of manuscript: Geon Ho Bahn. Agree with results and conclusions and accept final manuscript: all authors.

\section{ORCID}

Geon Ho Bahn https://orcid.org/0000-0002-3550-0422

Kyunghoon Seo https://orcid.org/0000-0002-8484-7625 


\section{REFERENCES}

1. Adler LA, Reingold LS, Morrill MS, Wilens TE. Combination pharmacotherapy for adult ADHD. Curr Psychiatry Rep 2006; 8:409-415.

2. Fujioka T, Takiguchi S, Yatsuga C, Hiratani M, Hong KE, Shin MS, et al. Advanced test of attention in children with attention-deficit/hyperactivity disorder in Japan for evaluation of methy/phenidate and atomoxetine effects. Clin Psychopharmacol Neurosci 2016;14:79-87.

3. Greenhill LL, Abikoff HB, Arnold LE, Cantwell DP, Conners $\mathrm{CK}$, Elliott $\mathrm{G}$, et al. Medication treatment strategies in the MTA Study: relevance to clinicians and researchers. I Am Acad Child Adolesc Psychiatry 1996;35:1304-1313.

4. Wagner KD. Management of treatment refractory attentiondeficit/hyperactivity disorder in children and adolescents. Psychopharmacol Bull 2002;36:130-142.

5. Kooij JJS. Adult ADHD: diagnostic assessment and treatment. 3rd ed. London:Springer;2013.

6. Treuer T, Gau SS, Méndez L, Montgomery W, Monk JA, Altin $\mathrm{M}$, et al. A systematic review of combination therapy with stimulants and atomoxetine for attention-deficit/hyperactivity disorder, including patient characteristics, treatment strategies, effectiveness, and tolerability. J Child Adolesc Psychopharmacol 2013;23:179-193.

7. Subcommittee on Attention-Deficit/Hyperactivity Disorder; Steering Committee on Quality Improvement and Management, Wolraich M, Brown L, Brown RT, DuPaul G, et al. ADHD: clinical practice guideline for the diagnosis, evaluation, and treatment of attention-deficit/hyperactivity disorder in children and adolescents. Pediatrics 2011;128:1007-1022.

8. Bahn GH, Lee YS, Yoo HK, Kim EJ, Park S, Han DH, et al. Development of the Korean practice parameter for adult attention-deficit/hyperactivity disorder. I Korean Acad Child Adolesc Psychiatry 2020;31:5-25.

9. Carlson GA, Dunn D, Kelsey D, Ruff D, Ball S, Ahrbecker L, et al. A pilot study for augmenting atomoxetine with methylphenidate: safety of concomitant therapy in children with attention-deficit/hyperactivity disorder. Child Adolesc Psychiatry Ment Health 2007;1:10.

10. Brown TE. Atomoxetine and stimulants in combination for treatment of attention deficit hyperactivity disorder: four case reports. J Child Adolesc Psychopharmacol 2004;14:129-136.

11. Ozbaran B, Kose S, Yuzuguldu O, Atar B, Aydin C. Combined methy/phenidate and atomoxetine pharmacotherapy in attention deficit hyperactivity disorder. World I Biol Psychiatry 2015; 16:619-624.

12. American Psychiatric Association. Diagnostic and statistical manual of mental disorders. 4th ed. Washing D.C.:American Psychiatric Publishing; 1994.
13. American Psychiatric Association. Diagnostic and statistical manual of mental disorders. 5th ed. Arlington:American Psychiatric Publishing;2013.

14. Bahn GH, Hong M, Lee YJ, Han J, Oh SH. Revisiting history of treatment of attention deficit hyperactivity disorder: pharmacologic approach. Korean J Biol Psychiatry 2014;21:37-48.

15. Hong M, Kim B, Hwang JW, Bhang SY, Choi HY, Oh IH, et al. Naturalistic pharmacotherapy compliance among pediatric patients with attention deficit/hyperactivity disorder: a study based on three-year nationwide data. J Korean Med Sci 2016; 31:611-616.

16. Pottegård A, Bjerregaard BK, Glintborg D, Kortegaard LS, Hallas J, Moreno SI. The use of medication against attention deficit/hyperactivity disorder in Denmark: a drug use study from a patient perspective. Eur J Clin Pharmacol 2013;69: 589-598.

17. van den Ban E, Souverein PC, Swaab $\mathrm{H}$, van Engeland $\mathrm{H}$, Egberts TC, Heerdink ER. Less discontinuation of ADHD drug use since the availability of long-acting ADHD medication in children, adolescents and adults under the age of 45 years in the Netherlands. Atten Defic Hyperact Disord 2010;2:213-220.

18. Zetterqvist J, Asherson $\mathrm{P}$, Halldner L, Långström N, Larsson $\mathrm{H}$. Stimulant and non-stimulant attention deficithyperactivity disorder drug use: total population study of trends and discontinuation patterns 2006-2009. Acta Psychiatr Scand 2013;128:70-77.

19. Hong M, Lee WH, Moon DS, Lee SM, Chung US, Bahn GH. $A$ 36 month naturalistic retrospective study of clinic-treated youth with attention-deficit/hyperactivity disorder. I Child Adolesc Psychopharmacol 2014;24:341-346.

20. Osland ST, Steeves TD, Pringsheim T. Pharmacological treatment for attention deficit hyperactivity disorder $(A D H D)$ in children with comorbid tic disorders. Cochrane Database Syst Rev 2018;6:CD007990.

21. Kim HW, Kim E, Kim JH, Park J, Bahn GH, Lee YJ, et al. The revised Korean practice parameter for the treatment of attention-deficit hyperactivity disorder (III)- pharmacological treatment-. J Korean Acad Child Adolesc Psychiatry 2017;28:70-83.

22. Muit JJ, Bothof N, Kan CC. Pharmacotherapy of $A D H D$ in adults with autism spectrum disorder: effectiveness and side effects. J Atten Disord 2020;24:215-225.

23. Kim YJ, Oh S, Lee J, Moon SJ, Lee WH, Bahn GH. Factors affecting adherence to pharmacotherapy in childrenwith attention-deficit hyperactivity disorder: a retrospective study. J Korean Acad Child Adolesc Psychiatry 2010;21:174-181.

24. Miller J, Perera B, Shankar R. Clinical guidance on pharmacotherapy for the treatment of attention-deficit hyperactivity disorder $(A D H D)$ for people with intellectual disability. Expert Opin Pharmacother 2020;21:1897-1913. 